\title{
Alianzas matrimoniales coloniales entre caciques mixtecos: El caso de Acatlan-Petlalcingo ${ }^{1}$
}

\author{
John K. Chance \\ Anthropology School of Human Evolution \\ and Social Change
}

Las alianzas matrimoniales entre familias gobernantes fueron un instrumento importante de integración política en la Mesoamérica Posclásica, especialmente en la Mixteca. Estas alianzas entre los nobles mixtecos persistieron a través de la época colonial, aunque después del siglo XVI los caciques perdieron mucho de su poder político ante los gobernadores y los Cabildos. En este ensayo investigo el significado de las alianzas entre caciques mixtecos por medio de los casamientos de ocho generaciones de la familia Villagómez de Acatlan y Petlalcingo, desde 1669 hasta mediados del siglo XIX. Sostengo que sólo el primero de estos enlaces matrimoniales fue políticamente estratégico.

PALABRAs Clave: Alianzas matrimoniales, caciques mixtecos, México, época colonial.

Marriage alliances among governing families were an important instrument of political integration in Postclassic Mesoamerica, especially in the Mixteca. Alliances among Mixtec nobles persisted during the colonial period, although after the sixteenth century the caciques lost much of their political power to the gobernadores and the Cabildos. In this essay I investigate the significance of alliances among Mixtec caciques through the marriages of eight generations of the Villagómez family of Acatlan and Petlalcingo, from 1669 until the mid-nineteenth century. I argue that only the first of these marriages was politically strategic.

Keywords: Marriage alliances, Mixtec caciques, Mexico, Colonial period.

\section{Introducción}

Las alianzas matrimoniales entre familias gobernantes fueron un instrumento importante de integración política en la Mesoamérica Posclásica.

1 Este trabajo se presentó en la XXVIII Mesa Redonda de la Sociedad Mexicana de Antropología, México, DF, en 9 de agosto de 2007. Agradezco a María Castañeda de la Paz y a Manuel A. Hermann Lejarazu su invitación a participar en el simposio sobre "La nobleza indígena colonial. Pervivencias y adaptaciones en el ocaso de su poder." Versiones previas de este trabajo se beneficiaron 
En una época en la que el paisaje político consistió en muchas pequeñas ciudades-estados en competencia, la alianza matrimonial fue una estrategia clave de expansión estatal, así como un mecanismo para guardar la paz y preservar el botín de guerra. En algunas regiones, especialmente en la Mixteca, estos enlaces entre nobles indígenas de diferentes señoríos persistirían a través del período colonial hasta entrar en el siglo XIX. Pero después del XVI, el contexto político había cambiado bastante. Teniendo que cargar con el dominio español y obligados a compartir el poder con los Cabildos, los nobles coloniales, o caciques, como les llamaron los españoles, perdieron mucho de su poder político formal. En este ensayo, quiero explorar el sentido y significado de las uniones matrimoniales entre caciques mixtecos en el contexto colonial a través de una mirada detallada a los casamientos de miembros de la familia Villagómez de los pueblos de Acatlan y Petlalcingo en la Mixteca Baja. Examinaré los casamientos de ocho generaciones de caciques Villagómez durante doscientos años, desde 1669 hasta mediados del XIX (véase Figura 1).

Los señoríos pequeños pero altamente estratificados de la Mixteca son bien conocidos por sus redes extensivas de alianzas matrimoniales, y Spores $^{2}$ sostiene que éstas fueron más importantes que las guerras de conquista en la expansión política mixteca. Las alianzas conectaban diferentes señoríos para formar los yuhuitayu. Estos estados complejos se formaban cuando la novia y el novio eran, cada uno, herederos de un señorío autónomo, o ñuu, con su casa noble, o aniñe. Más tarde los españoles designaron los ñu y yuhuitayu como cacicazgos, sobre el modelo de los mayorazgos. ${ }^{3}$

En otro lugar he sostenido que el estatus noble mixteco después de la invasión española se reconstituyó en una base principalmente económica. ${ }^{4}$

de los comentarios de Patricia Cruz Pazos, Barbara Stark y Michael E. Smith. William Autry y Margarita Menegus Bornemann también hicieron comentarios provechosos. Agradezco especialmente a John Monaghan por compartir conmigo sus conocimientos de la Mixteca y por su asistencia con partes de la genealogía de la familia Villagómez. Cualquier error que queda es mío. Una beca de FulbrightHays apoyó mis investigaciones de archivo.

2 Spores, Ronald: "Marital Alliance in the Political Integration of Mixtec Kingdoms", American Anthropologist, vol. 76 (2), 1974, pág. 302.

3 Terraciano, Kevin: The Mixtecs of Colonial Oaxaca, Stanford University Press, Stanford CA, 2001, pág. 158 .

4 Chance, John K.: "Indian Elites in Late Colonial Mesoamérica", en Marcus, Joyce and Francis Zeitlin, Judith (eds.): Caciques and Their People: A Volume in Honor of Ronald Spores, Anthropological Papers Núm. 89. Museum of Anthropology, University of Michigan, Ann Arbor, MI, 1994, pág. 48. 


\section{FIGURA 1}

\section{CASAMIENTOS Y CACICAZGOS DE LOS CACIQUES VILLAGÓMEZ DE ACATLAN-PETLALCINGO}

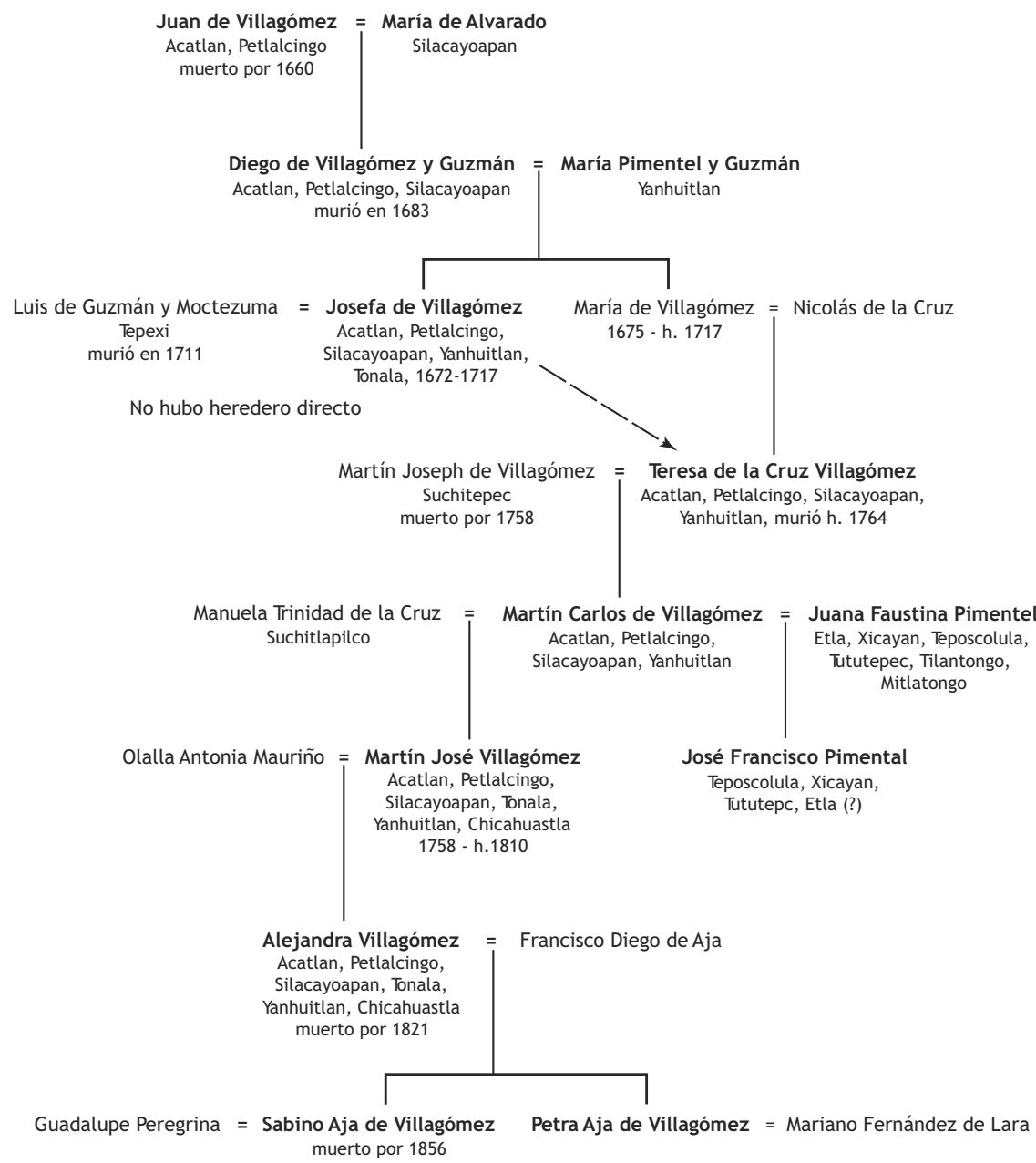

Nota: Nombres de herederos de cacicazgos están en negritas. 
La riqueza adquirida con la explotación de tierras, la mano de obra de terrazgueros y el comercio se convirtieron en el fundamento principal del estatus del cacique colonial. El ejercicio del poder político se volvió cada vez más problemático a través del tiempo. Empezando el siglo XVII, la posición política de muchos nobles en la Mixteca disminuyó, igual que en el Valle de Oaxaca. ${ }^{5}$ Los caciques tenían que compartir el poder en sus comunidades con los Cabildos y los gobernadores. Durante el siglo XVI, los gobernadores y los caciques eran generalmente la misma persona, ${ }^{6}$ pero más tarde fueron con frecuencia diferentes. En muchas comunidades, los caciques coloniales tardíos no ocupaban puestos políticos formales, ni aspiraban a ocuparlos. Se apartaron, física y psicológicamente, de los macehuales, trasladándose a ranchos rurales o a las ciudades de Puebla, Huajuapan, u Oaxaca. Mientras estos caciques a veces eran influyentes políticamente entre bastidores, la mayoría se preocupaba más por sus propiedades — si las tenían- que por los asuntos políticos de la comunidad. En ambas zonas, la Mixteca y el Valle de Oaxaca, los caciques coloniales tardíos dejaron de manejar sus propias haciendas y empezaron a darlas en arriendo y a vivir de las rentas. ${ }^{7}$ Mientras esta práctica no imposibilitó a muchos caciques mixtecos de reclutar terrazgueros y así mantenerse influyentes en la sociedad rural, ${ }^{8}$ sus relaciones con los Cabildos se pusieron más tensas y distantes a través del tiempo.

La persistencia de las alianzas matrimoniales en este contexto plantea varias preguntas. ¿Ahora que menos caciques dominaban la política local, sus alianzas matrimoniales eran todavía "estratégicas"?, ¿contribuyeron las alianzas a la integración política de comunidades coloniales?, ¿cuáles fueron su sentido y significado social?, ¿cuán efectivos fueron bajo las condiciones coloniales?, ¿cómo cambiaron a través del tiempo? El estudio del caso que sigue tiene la finalidad de ayudar a contestar estas preguntas.

5 Ibídem, pág. 48. Pastor, Rodolfo: Campesinos y reformas:La Mixteca, 1700-1856, El Colegio de México, México, 1987, págs. 81-82. Taylor, William B.: Landlord and Peasant in Colonial Oaxaca, Stanford University Press, Stanford, CA, 1972, pág. 48.

6 Spores, Ronald: The Mixtecs in Ancient and Colonial Times, University of Oklahoma Press, Norman, OK, 1984, pág. 168.

7 Monaghan, John; Joyce, Arthur y Spores, Ronald: "Transformations of the Indigenous Cacicazgo in the Nineteenth Century", Ethnohistory, vol. 50 (1), 2003, pág. 135. Taylor, William B.: Landlord and Peasant..., págs. 57, 65-66.

8 Monaghan, Joyce y Spores: “Transformation...”, pág. 135. 
La familia Villagómez ${ }^{9}$ estaba estrechamente vinculada con el pueblo de Acatlan (Yucuyuchi en mixteco), una comunidad mixteca en su mayor parte, pero con una minoría nahua. ${ }^{10}$ No se sabe si los Villagómez descendían de los mandones prehispánicos de Acatlan, y es posible que ascendieran al poder después de la conquista española. ${ }^{11}$ El primer noble con este apellido que he encontrado fue Cristóbal de Villagómez, un principal y gobernador de Petlalcingo en $1576 .{ }^{12}$ Veremos que los cacicazgos de Acatlan y Petlalcingo fueron vinculados durante toda la época colonial y más allá. Junto con otros lugares, formaron el cacicazgo más grande en la Mixteca Baja.

\section{Alianza con Yanhuitlan}

Si el cacicazgo Villagómez fue el más grande y prestigioso en la Baja desde comienzos del siglo XVII, los cacicazgos vinculados de Yanhuitlan

9 Otros tratamientos de aspectos del cacicazgo Villagómez de Acatlan-Petlalcingo desde varios puntos de vista incluyen Alfonso Caso: "The Lords of Yanhuitlan" en Paddock, John (ed.): Ancient Oaxaca. Stanford University Press, Stanford, CA, 1966, págs. 313-335; Smith, Mary Elizabeth y Parmenter, Ross: The Codex Tulane. Publication Núm. 61, Middle American Research Institute, Tulane University, New Orleáns, LA, 1991; y John Monaghan: "Mixtec Codices and the Transition from Noble Estates to Corporate Communities in the Nineteenth Century" en Boone, Elizabeth Hill (ed.): Painted Books and Indigenous Knowledge in Mesoamerica: Manuscript Studies in Honor of Mary Elizabeth Smith. Publication Núm. 69, Middle American Research Institute, Tulane University, New Orleáns, LA, 2005, págs. 415-426. El presente trabajo agrega unos detalles nuevos sobre la genealogía colonial de esta familia bien conocida.

10 Smith, Michael E. y Berdan, Frances F.: "Appendix 4: Province Descriptions" en Berdan, Frances F. , Blanton, Richard E., Boone, Elizabeth Hill, Hodge, Mary G., Smith, Michael E. and Umberger, Emily: Aztec Imperial Strategies, Dumbarton Oaks, Washington, D.C., 1996, pág. 284.

11 El apellido Villagómez posiblemente fue tomado en recuerdo de don Fernando de Villagómez, obispo de Puebla entre 1562 y 1571. Cordero y Torres, Enrique: Diccionario biográfico de Puebla, vol. 2, Fotolitográfica Leo, México, 1973, pág. 705. Monaghan observa que un descendiente de los Villagómez en el siglo XIX, Leonardo Aja, reclamó su descendencia del cacique don Carlos de Austria, señor de Teposcolula en la Mixteca Alta en 1531 (posiblemente Ya qua en los codices mixtecos). Destaca también que es muy probable que varios miembros de la familia Villagómez en los siglos XVIII y XIX poseían códices mixtecos, inclusive el Códice Tulane, el Códice de Yanhuitlan, el Códice Becker I, la porción Colombino del Colombino-Becker, y el Becker II. Monaghan, John: "Mixtec Codices...”, pág. 422. Smith y Parmenter: The Codex Tulane..., pág. 68. Sospecho que la conexión de los Villagómez con Teposcolula ocurrió con el casamiento de don Diego de Villagómez y Guzmán con doña María Pimentel y Guzmán de Yanhuitlan en 1669 (véase Figura 1). El padre de doña María, don Francisco Pimentel y Guzmán, heredó el cacicazgo de Teposcolula de su madre, aunque es dudoso que lo legara a su hija. Pastor, Rodolfo: "Apéndices al subcapítulo sobre los cacicazgos: Crónicas paralelas de los caciques y galerías de retratos familiares" en Campesinos y reformas: La Mixteca, 1748-1856. Vol. 2, Capítulo 3. Tesis de doctorado inédita, El Colegio de México, México, 1981, pág. 12. En 1739, don Martín Carlos de Villagómez se casó con otra heredera de Teposcolula, doña Juana Faustina Pimentel, pero no hay evidencia de que Teposcolula fuera parte importante del cacicazgo Villagómez (véase Figura 1).

12 Archivo General de la Nación, México (en adelante AGN), Indios 1, exp. 69, fol. 27. 
(Yodzocahi) y Teposcolula (Yucundaa), en la Mixteca Alta, contaban entre los más grandes, ricos y prestigiosos en cualquier parte de toda la Mixteca. Un evento político de gran importancia ocurrió en 1669 cuando doña María Pimentel y Guzmán, hija del cacique de Yanhuitlan don Francisco Pimentel y Guzmán, se casó con don Diego de Villagómez y Guzmán, heredero de los cacicazgos en la Baja de Acatlan, Petlalcingo, San Jerónimo, Santo Domingo Tonahuixtla y Silacayoapan (véase Figura 1). El padre de doña María también tomó la medida poco común de renunciar a su título de cacique de Yanhuitlan y traspasar ese cacicazgo a su hija y a su esposo al tiempo de su enlace.

Este casamiento probablemente pareció insólito en esa época. Aún un cacicazgo acomodado de la Baja como Acatlan carecía de la riqueza, prestigio e historia ilustre de los señoríos grandes de la Alta. Pero por los años 1660, todo había cambiado mucho. Esto fue sólo cuatro décadas después del punto más bajo de la declinación de población en la Mixteca, y las comunidades eran más pequeñas y más pobres que antes. ${ }^{13}$ Esa decadencia no sólo empobreció a muchos nobles, sino que también se les hizo más difícil encontrar cónyuges apropiados en comunidades cercanas, teniendo que buscarlos en partes más distantes. ${ }^{14}$

La alianza entre don Diego y doña María llevaba riesgos, pero la riqueza de ambos (en esa época) y sus intereses comunes de clase aseguraron que valía la pena tomarlos. Para don Diego, el casamiento fue la oportunidad de forjar lazos con un cacicazgo ilustre con más prestigio que el suyo. Para doña María, significó la posibilidad de mejorar su riqueza y posición, y tal vez su nivel de vida. El casamiento juntó en un solo yuhuitayu derechos en seis comunidades en la Alta y Baja, estableciendo un precedente significativo en el siglo XVII. Desgraciadamente, hay poca información sobre cómo la pareja manejaba sus propiedades diversas o donde residieron. Como conjunta persona de su esposa, don Diego se hizo el cacique titular de Yanhuitlan, pero doña María poseyó sus derechos y propiedades por separado y a su muerte también los legó separadamente.

13 Según William Autry, la población de la Mixteca empezó a recuperarse en los 1620. Comunicación personal, 4 de noviembre de 2006.

14 La Mixteca es bien conocida por sus casamientos nobles entre comunidades distantes, especialmente en la época prehispánica. Pero en la época colonial antes de 1670, los caciques de Yanhuitlan habían encontrado sus cónyuges en pueblos cercanos de la Mixteca Alta, inclusive TamazolaChachoapan, Achiutla, Tlaxiaco, y Teposcolula. Spores, Ronald: The Mixtec Kings and Their People, University of Oklahoma Press, Norman, OK, 1967. Terraciano, Kevin: The Mixtecs..., págs. 175-177. 
Una cuestión importante relativa a la integración política es hasta qué punto caciques como don Diego lograron ejercer poder político en los cacicazgos de sus mujeres. No sabemos si don Diego sirvió como gobernador en algunos de sus pueblos en la Mixteca Baja, pero a los ojos de algunos de sus súbditos en Yanhuitlan, el cacique gozó algunas de las prerrogativas políticas de sus antecesores del siglo XVI y recibió el apoyo de los gobernadores del pueblo. ${ }^{15}$

Don Diego murió en 1683 en su rancho Misquitlixco, cerca de Petlalcingo, catorce años después de hacerse cacique de Yanhuitlan. Doña María ya había muerto antes, y la pareja dejó dos hijas, Josefa de 11 años, y María de 8 años de edad. Aunque don Diego fue un cacique rico para su tiempo, sus posesiones materiales y estilo de vida se comparan desfavorablemente con los de los grandes caciques del siglo XVI, como don Gabriel de Guzmán de Yanhuitlan. ${ }^{16}$ Como la propiedad movible de don Gabriel, la de don Diego fue principalmente de estilo español, aunque sus muebles de casa eran modestos. Igual que la mayoría de sus contemporáneos, don Diego fue activo en el comercio y a su muerte dejó en su casa una gran cantidad de algodón y 500 piezas de loza poblana. Sus negocios se concentraban en Silacayoapan, y en su testamento no menciona intereses económicos en Yanhuitlan ni en otra parte de la Mixteca Alta. Parece que don Diego se sintió como en casa igualmente en los mundos mixteco y español. Hablaba bien el castellano y dictó su testamento en esa lengua. Nombró a sus dos hijas herederas por iguales partes, desviando de la costumbre de escoger un solo heredero para recibir el cacicazgo. ${ }^{17}$

\section{Una alianza fracasada en el siglo XVII tardío}

El cacicazgo Villagómez se estancó después de la muerte de don Diego. Sus dos hijas jóvenes residieron en Acatlan, y la menor cedió su parte de la herencia a la mayor, doña Josefa de Villagómez. ${ }^{18}$ En 1691, a la edad de 19 años, doña Josefa se casó con don Luis de Guzmán Moctezuma,

15 Archivo Histórico Judicial de Oaxaca (en adelante AHJO), Teposcolula Civil, 15, exp. 25; AGN Tierras 400, exp. 1, fol. 80.

16 Spores, Ronald: The Mixtec Kings..., págs. 164-170.

17 AGN, Tierras, 400, exp. 1, fols. 111v-116v.

18 Biblioteca Nacional, México. Sección Tenencia de la Tierra en Puebla (en adelante BN), 1, exp. 172 , fol. $36 \mathrm{v}$. 
un noble de Tepexi de la Seda, una comunidad de lengua nahua y popoloca al norte de la Mixteca Baja. ${ }^{19}$ Por entonces, ésta había heredado los cacicazgos de sus padres, y fue conocida como cacica de Acatlan, Petlalcingo, Silacayoapan, Tonala, y Yanhuitlan, junto con el barrio San Jerónimo Silacayoapilla y San Pedro Mártir en la Baja. ${ }^{20} \mathrm{Su}$ esposo, actuando en su nombre, tomó posesión de todos estos cacicazgos en 1697, quejándose del estado desordenado en que habían caído. ${ }^{21}$ El centro de estas tenencias dispersas permaneció en la Mixteca Baja, pero en el mismo año que tomó posesión, don Luis logró hacerse elegir gobernador en Yanhuitlan, a pesar de cierta oposición..$^{22}$

Desde un punto de vista político-económico, la alianza de doña Josefa con un noble mucho menos acomodado, y sin cacicazgo propio, fue para ella un paso hacia atrás, que le reportaba pocas ventajas. Tepexi era menos prominente que Acatlan, y don Luis, a pesar de que sus padres eran caciques, creció pobre y sin herencia propia en la casa de unos parientes. Todas estas circunstancias indican que doña Josefa se casó por razones más personales que estratégicas.

Si el cacicazgo Villagómez fue mal manejado cuando doña Josefa lo heredó, los problemas aumentaron después de su enlace. Don Luis inmediatamente tomó el control y pronto adquirió una reputación de matón. En Acatlan, donde el cacicazgo tenía unos ingenios de azúcar, los sentimientos en su contra aumentaron hasta el punto de que fue desterrado del pueblo por el alcalde mayor. La pareja se cambió luego a Tepexi, donde don Luis fue asesinado en 1710, no dejando testamento ni descendientes. ${ }^{23}$ Doña Josefa sobrevivió a su esposo siete años, y al tiempo de su muerte en su rancho en Petlalcingo en 1717, anotó amargamente en su testamento que don Luis había consumido y gastado imprudentemente la mayor parte de su fortuna, forzándola a contraer varias deudas. Al morir la cacica sin hijos, legó su cacicazgo a la hija de su hermana, doña Teresa de la Cruz Villagómez Pimentel y Guzmán. ${ }^{24}$

19 AGN, Indios, 36, exp. 78, fol. 79.

20 BN 1, exp. 172.

21 Pastor, Rodolfo: “Apéndices...”, pág. 14.

22 Ibídem. BN 2, exp. 199.

23 Cruz Pazos, Patricia: La nobleza indígena de Tepexi de la Seda durante el siglo XVIII: La cabecera y sus sujetos, 1700-1786. Tesis de doctorado inédita, Universidad Complutense de Madrid, Madrid, 2007, págs. 109-116. BN 1, exp. 172; 2, exp. 199.

24 AGN, Tierras, 400, exp. 1, fols. 138-141. 


\section{Una repulsa de Yanhuitlan}

Mientras el matrimonio de doña Josefa le había causado mucha frustración y decepción, su sobrina y heredera contrajo una alianza tan políticamente tumultuosa que extinguió la mayoría de lo que quedó de la autoridad del cacique en Yanhuitlan. En 1717, doña Teresa se había casado con don Martín Joseph Villagómez Guzmán y Mendoza, un hombre ambicioso de San Juan Suchitepec, en la Mixteca Baja. ${ }^{25}$ Aunque los contrayentes tenían el mismo apellido, eran de diferentes familias y el cacicazgo de Suchitepec —en manos del padre de don Martín Joseph hasta su muerte en 1715- era más pequeño que los de Acatlan-Petlalcingo y Yanhuitlan. ${ }^{26}$ Además, don Martín no sucedió a su padre en el cacicazgo, y su única herencia en Suchitepec fue un rancho. Fue un individuo inquieto y codicioso, que había viajado mucho.

Por segunda vez, la heredera del cacicazgo más grande en la Mixteca escogió un esposo, que, aunque de nacimiento noble, no tuvo derecho propio de cacicazgo. De nuevo parece que las calidades personales pesaban más que las consideraciones estratégicas. Doña Teresa, residente de Acatlan, no estaba en la línea recta de sucesión, y probablemente no creció contando con heredar el cacicazgo. Después de su boda, su esposo tomó posesión del cacicazgo en su nombre, ${ }^{27}$ e inmediatamente encontró resistencia cuando trató de hacerse elegir gobernador de Yanhuitlan. ${ }^{28}$ Pero lo que más molestó a los yanhuitecos fue la pretensión atrevida de don Martín Joseph de que, como conjunta persona de su esposa, tenía derecho a todas las tierras del pueblo y a que todos los yanhuitecos fueron sus terrazgueros. ${ }^{29}$ Cuarenta años antes, el gobernador de Yanhuitlan había atribuido esta clase de autoridad al cacique don Diego de Villagómez. Pero éste había sido más prudente y delegó el control sobre muchas tierras a caciques locales secundarios; nunca, que sepamos, tuvo pretensiones tan dogmáticas como don Martín Joseph.

25 Pastor, Rodolfo: “Apéndices...”, pág. 16.

26 Los Villagómez de Acatlan-Petlalcingo y de Suchitepec probablemente estuvieron emparentados, pero distantemente. No hay constancia del apellido Villagómez en Suchitepec antes de principios del siglo XVIII.

27 AGN, Tierras, 985, exp. 1.

28 Terraciano, Kevin: The Mixtecs..., pág. 195.

29 Pastor, Rodolfo: “Apéndices...”, pág. 16. 
Esas demandas cacicales a derechos tan fundamentales sobre tierras y terrazgueros tenían precedentes amplios en muchos cacicazgos más pequeños, más pobres y menos urbanizados en la Mixteca Baja, incluyendo a Suchitepec, el pueblo natal de don Martín Joseph. Pero en un pueblo grande y cosmopolita de la Mixteca Alta como Yanhuitlan, tales pretensiones fueron vistas como exageradas. Es posible que esto fuera una diferencia regional entre los cacicazgos de la Mixteca Baja y los de la Alta, ${ }^{30}$ y ayudaría a explicar porqué don Martín Joseph y los yanhuitecos nunca se entendieron. El Cabildo de Yanhuitlan sostuvo que las tierras del cacicazgo y del pueblo eran distintas y separadas, aún en tiempos prehispánicos, y que don Martín Joseph sólo podía funcionar como cacique en su pueblo de origen, no en Yanhuitlan. ${ }^{31}$ Este pleito continuó en la Real Audiencia de México, sin resolverse durante muchos años. El cacique, residiendo con su esposa en el rancho Villagómez en Petlalcingo, se sintió terriblemente decepcionado por la repulsa de los yanhuitecos y cambió su enfoque a las propiedades más seguras que su esposa tenía en la Baja. Se estableció por un tiempo en Silacayoapan, donde sirvió de gobernador entre 1719 y 1724.

Pero don Martín Joseph nunca abandonó su sueño de ser cacique de Yanhuitlan, no solamente por el prestigio que llevaba la posición, sino también por los beneficios económicos que le traerían las tierras de ese cacicazgo. Hasta hipotecó en 1723 el cacicazgo de Acatlan por 6.000 pesos para poder invertir más en algunos ranchos y financiar su pleito con Yanhuitlan. ${ }^{32}$

Finalmente, don Martín Joseph perdió su pleito con Yanhuitlan antes de fallecer un poco después de 1730. Su viuda apeló la sentencia, pero encontró poco apoyo en la comunidad - aunque era la heredera legítimay en 1758 la Audiencia de México falló por segunda vez a favor del pueblo, dejando por primera vez la autoridad cacical en Yanhuitlan sin reconocimiento legal. Varios factores contribuyeron a este resultado: entre ellos el hecho de que don Martín Joseph fue un noble sin cacicazgo de un pueblo menos prestigioso que Yanhuitlan en la Mixteca Baja, su personalidad agresiva, el poder creciente del Cabildo yanhuiteco y las diferencias culturales y políticas entre los cacicazgos de la Alta y la Baja. Además, la pareja residía principalmente en Petlalcingo, y hasta cierto punto fueron vistos como "extranjeros" en Yanhuitlan. Al tiempo de su muerte en 1764, las

30 Terraciano, Kevin: The Mixtecs..., pág. 349.

31 AGN, Tierras, 400, exp. 1, fols. 9v, 87.

32 AGN, Indios, 48, exp. 156. 
propiedades de doña Teresa se localizaron principalmente en la Mixteca Baja, igual que en generaciones pasadas.$^{33}$ La pérdida de Yanhuitlan fue un golpe mayor para los Villagómez, pero si vemos el patrimonio de doña Teresa en su totalidad, sólo Yanhuitlan afrontó un desafío tan infatigable a los privilegios del cacicazgo.

\section{Una alianza prestigiosa con la Costa y el Valle de Oaxaca}

A pesar del rechazo de don Martín y doña Teresa por parte de Yanhuitlan, el matrimonio de su hijo y heredero, don Martín Carlos de Villagómez, confirmó que ese apellido todavía tenía un prestigio considerable a los ojos de otros caciques mixtecos. En 1739, don Martín Carlos contrajo una alianza altamente ventajosa que sobre el papel, al menos, le dio a él y a su novia más títulos de cacicazgos que los que cualquier otro cacique mixteco había reunido en la época colonial. Su esposa, doña Juana Faustina Pimentel Guzmán y Ramírez de León, fue hija y heredera de don Agustín Carlos Pimentel y Guzmán, cacique de Teposcolula, y de doña Nicolasa Ramírez de León, heredera del cacicazgo mixteco de Etla, el más grande en el Valle de Oaxaca.

Los oficiales españoles llamaron a doña Juana Faustina "la cacica de la Villa de Etla y de las provincias de Tututepec, Xicayán Y Costa del Mar del Sur." ${ }^{34}$ En realidad, el casamiento de esta pareja unió los cacicazgos de Acatlan, Petlalcingo, Silacayoapan, y Tonala ${ }^{35}$ en la Mixteca Baja; Teposcolula, Tilantongo, Mitlatongo, y unos restos de Yanhuitlan en la Alta; Etla en el Valle de Oaxaca; y Tututepec y Jamiltepec en la costa. Tal unificación trascendental de títulos no había ocurrido desde el tiempo del rey 8 Venado en el siglo XII. Pero hubo una diferencia notable: esta pareja no hizo ningún esfuerzo para integrar sus jurisdicciones políticamente, ya que dado el contexto colonial tardío, eso hubiera sido imposible. Los caciques residie-

33 Archivo General del Estado de Oaxaca, Alcaldes Mayores 56, exp. 16.

34 AGN, Tierras, 704, exp. 5.

35 El papel de Tonala en el cacicazgo Villagómez es ambiguo. Parece que la familia Villagómez tenía tierras y tal vez otros derechos en unos sujetos, pero no en la cabecera de Tonala hasta el fin del siglo (véase nota 38). Los caciques más importantes de esta cabecera tenían los apellidos Guzmán y De la Cruz. García Alcaraz, Agustín: Tinujei: Los triquis de Copala. Segunda edición. Centro de Investigaciones y Estudios Superiores en Antropología Social, México, 1997, págs. 210-229. Menegus Bornemann, Margarita: "Gobierno y territorialidad en la Mixteca. Permanencia y cambio en el siglo XVI." Ponencia presentada en la XXVIII Mesa Redonda de la Sociedad Mexicana de Antropología, México, D.F., 9 de agosto de 2007, págs. 14-17. 
ron en el rancho Villagómez en Petlalcingo y mantenían relaciones distantes con sus súbditos y propiedades, que ellos vieron no en términos de derechos políticos, sino más bien como fuentes de ingresos. Ambos hablaban bien el castellano como sus padres, y probablemente tenían un estilo de vida parecido al de muchos españoles de la época, aunque eran más ricos que los hacendados importantes oaxaqueños. Pero los conflictos serios entre cacicazgos y pueblos en la Mixteca habían comenzado, y correspondió a la próxima generación de Villagómez el ocuparse de ellos.

\section{Del mundo mixteco al mundo español}

Doña Juana Faustina y don Martín Carlos tuvieron un hijo, don José Francisco Pimentel y Guzmán, quién heredó el cacicazgo de Teposcolula, los de la costa, y tal vez el de Etla también de su madre. Doña Juana murió antes que su esposo, quien se casó por segundas nupcias con doña Manuela Trinidad de la Cruz, una cacica de Santa María Suchitlapilco, una comunidad pequeña cercana a Tonala, en la Mixteca Baja. ${ }^{36}$ De esta pareja tuvo también un hijo, don Martín José Villagómez Pimentel de la Cruz Guzmán, quien heredó el cacicazgo Villagómez cuando se murió su padre. Tomó el control en 1778, a la edad de 20 años. ${ }^{37}$

Don Martín José fue conocido como "cacique de las dos Mixtecas, Alta y Baja", reclamando los cacicazgos de Acatlan, Petlalcingo, Silacayoapan, y Tonala en la Baja; y Teposcolula y Chicahuastla en la Alta. ${ }^{38}$ Pero Teposcolula probablemente quedó en manos de su medio hermano o sus descendientes, y don Martín José no fue mejor recibido en Yanhuitlan que su padre o abuela. Este cacique residió en Petlalcingo y se sostenía rentando sus tierras a labradores y hacendados españoles y a comunidades mixtecas. Con el transcurrir del siglo XVIII, los derechos de

36 AGN, Tierras, 985, exp. 1, fol. 10; 1209, exp. 6; 1373, exp. 4.

37 Pastor, Rodolfo: “Apéndices...”, págs. 22-23. AHJO, Teposcolula Civil, 48, exp. 22, fol. 284v; AGN, Tierras, 986, exp. 1.

38 AGN, Tierras, 985, exp. 1, fol. 10; 2953, exp. 105; 2702, primera parte, exp. 5. El cacicazgo que abarcaba las cabeceras de Tonala, Chicahuastla, y Copala quedó vacante en 1776 cuando el cacique don Juan Antonio de la Cruz Guzmán murió sin herederos. Don Martín José Villagómez lo reclamó en 1778, alegando que don Juan Antonio fue su "tío abuelo". El lazo de parentesco probablemente fue por la madre de don Martín José, doña Manuela Trinidad de la Cruz (véase Figura 1). La Audiencia de México aprobó la petición de don Martín José en 1779, pero la resistencia local y la falta de dinero para pagar los derechos legales (1.000 pesos, una suma grande) aplazaron su control sobre las tierras hasta después de 1806. García Alcaraz, Agustín: Tinujei..., págs. 210-229. Monaghan, John: "Mixtec Codices...”, págs. 416-417. 
cacicazgo se concentraron más y más en la propiedad privada de tierras al estilo español. La preocupación más grande de los caciques venía de comunidades como Yanhuitlan que desafiaron sus derechos a tierras en los juzgados y frecuentemente se negaron a reconocerlos como tales caciques. Las presiones legales y financieras llegaron a un punto decisivo para don Martín José en 1790, cuando gastaba tanto en los pleitos que careció de los fondos para manejar adecuadamente sus propiedades. Aunque fue uno de los terratenientes más grandes en el sur de México de su tiempo, ${ }^{39} \mathrm{el} \mathrm{caci-}$ que estaba en posesión efectiva de menos de la mitad de sus tierras e involucrado en 18 pleitos, un número asombroso aún para el patrón alto de la época. ${ }^{40}$ Diez de los litigios eran con comunidades mixtecas, seis con otros caciques y dos con españoles.

Aunque dominaba la lengua mixteca, don Martín José fue el primer Villagómez que se casó con una española, doña Olalla Antonia Mauriño, ${ }^{41}$ con lo cual se mostraba que estaba más cercano que sus padres a la identidad española. Su hija y heredera, doña Alejandra Manuela Teresa Villagómez Pimentel Guzmán de la Cruz Fonseca y Maldonado, parecía aún más apartada de las raíces mixtecas de su familia. Creció en la ciudad de Puebla y se murió de un accidente en $1821 .{ }^{42}$ Doña Alejandra fue la única Villagómez que llegó a casarse con un español peninsular, don Francisco Diego de Aja, residente en Acatlan. Don Francisco manejaba su cacicazgo y, aunque era europeo, se conocía en la región como "cacique y principal de estas Mixtecas." Él y su esposa dividieron su tiempo entre el rancho Tianguistengo en Petlalcingo y el pueblo de Molcaxac, al norte y fuera de la Mixteca. ${ }^{43}$ Sus dos hijos, Sabino Martín Carlos Aja de Villagómez y Petra Antonia Francisca Aja de Villagómez, ponen fin a esta historia. Aunque heredaban un cacicazgo grande, en sus manos dejó de ser "mixte-

39 Monaghan, John: "Mixtec Codices...”, pág. 416.

40 AGN, Tierras, 1209, exp. 6.

41 Archivo General de Notarías de Puebla (en adelante AGNP), Acatlan 3, Protocolo de 1821, cuaderno 6, fols. 2-4v. Monaghan, John: "Mixtec Caciques in the Nineteenth and Twentieth Centurias" en Jansen, Maarten y Reyes, Luis (Coords.): Codices, Caciques, y Comunidades. Cuadernos de Historia Latinoamericana Núm. 5, Asociación de Historiadores Latinoamericanistas Europeos, Leiden, 1997, pág. 269. Monaghan, John: "Mixtec Codices...” pág. 416.

42 Monaghan, John: "Indigenous Nobles, Political Bosses, and the Meaning of the Term Cacique in the Historical Discourse of the Mixteca, 1820-2000.” Ponencia presentada en la reunión anual de la American Society for Ethnohistory, Santa Fe, NM, 17 de noviembre de 2005, pág. 8. Don Martín José también tenía otra hija, Victoria Honorífica, quien se casó y residió en Petlalcingo. Monaghan, John: Comunicación personal, 4 de noviembre de 2006.

43 AGNP, Acatlan, 3, Protocolo de 1819, núm. 2; AGN, Tierras, 985, exp. 1. 
co" en algún sentido significativo. Aparte de su riqueza, las identidades y estilo de vida de estos hermanos parecen indistinguibles de los de otros criollos de la época. En efecto, frecuentemente eran conocidos y considerados como españoles. ${ }^{44}$

El cacicazgo que dejó doña Alejandra a sus dos hijos fue notable por su tamaño y por el hecho de que dividió sus propiedades igualmente entre ambos hijos, en lugar de dejar todo a un solo heredero. ${ }^{45}$ Cada heredero recibió tierras valoradas en más de 65.000 pesos. Éste fue el cacicazgo más grande en la Mixteca al entrar el siglo XIX, y casi todas sus tierras estaban rentadas. No he podido identificar todos los pedazos individuales, pues no he encontrado propiedades inventariadas en Yanhuitlan, Teposcolula, ni en otra parte de la Mixteca Alta, aparte de parcelas en los pueblos triquis de Chicahuastla y Copala ${ }^{46}$ Este cacicazgo terminaría donde empezó, en la Mixteca Baja.

Doña Petra y don Sabino crecieron en un nuevo país independiente donde se estaban eliminando las leyes españolas de mayorazgo; además, los títulos nobles perdieron su base legal y muchas comunidades mixtecas redoblaron sus esfuerzos para conseguir el control de las viejas tierras de cacicazgo. Doña Petra se casó con un español, don Mariano Fernández de Lara, y pasó su vida en la ciudad de Puebla; don Sabino contrajo matrimonio con una mujer de Tecali, Puebla, doña Guadalupe Peregrina, probablemente española también, y residió en Molcaxac. Después de la muerte de su primera esposa, don Sabino se casó de nuevo dos veces y regresó a Acatlan, donde su hijo, Leonardo Aja, fue jefe político en $\operatorname{los} 1870 .{ }^{47}$ Entre 1830 y los 1860 , los Aja vendieron grandes porciones de sus tierras, muchas a asociaciones agrícolas en pueblos que anteriormente las habían trabajado como terrazgueros. ${ }^{48}$ Con la muerte de doña Petra y don Sabino en los 1850 , el cacicazgo Villagómez dejó de existir como una entidad formal.

44 Monaghan, John: "Mixtec Cacique Marriages.” Ponencia presentada en la reunión anual de la American Society for Ethnohistory, Williamsburg, VA, 4 de noviembre de 2006.

45 AGNP, Acatlan, 3, Protocolo de 1821, cuaderno 6, fols. 2-4v. Es difícil determinar si había razones legales detrás de su decisión de dividir el cacicazgo. La práctica legal de vinculación de los cacicazgos y mayorazgos se abolió por las Cortes españolas en 1820, aunque no tuvo efecto en México oficialmente hasta 1823. Monaghan, John: "Indigenous Nobles...”, pág. 3.

46 Monaghan da detalles sobre ventas de las tierras del cacicazgo Villagómez en el siglo XIX. Monaghan, John: "Mixtec Codices...”, pág. 419.

47 Monaghan, John: Comunicación personal, 4 de noviembre de 2006.

48 AGNP, Acatlan, 4, Protocolos de 1830, 1833, 1835, 1837, 1838, 1839, 1840, 1841, 1845; AHJO, Huajuapan Civil, 16, exp. 4; 17, exp. 12; 22, exp. 14; 27, exps. 1 y 3. Véase también a Monaghan, John: "Indigenous Nobles..." y "Mixtec Codices...". 


\section{Conclusión}

Para entender el sentido y valor de estos casamientos, hay que reconocer que las alianzas no tuvieron lugar entre señoríos independientes, sino entre pueblos colonizados. La dimensión política de estas uniones disminuyó considerablemente en los siglos XVII y XVIII, y los contrayentes pusieron énfasis sobre otros varios factores, especialmente la identidad étnica, la clase social, y el bienestar material. Pero hemos visto que algunos de los caciques Villagómez o sus cónyuges tenían influencia política y podemos preguntarnos si cualquiera de estas alianzas matrimoniales fue estratégica políticamente. Mi respuesta es que sólo la primera lo fue. La alianza de 1669 entre don Diego de Villagómez de Acatlan-Petlalcingo y doña María Pimentel de Yanhuitlan fue una acción audaz que tendría consecuencias significativas para las cinco generaciones siguientes.

Los demás casamientos revisados aquí parecen débiles desde un punto de vista político. Ambos matrimonios de las herederas femeninas con nobles de Tepexi y Suchitepec fueron especialmente problemáticos. No hay razones aparentes del porqué esas alianzas con estas dos comunidades beneficiarían a los Villagómez y de que ninguno de los novios había heredado un cacicazgo en su pueblo natal. Ambos, don Luis de Guzmán y don Martín Joseph de Villagómez, explotaron implacablemente el cacicazgo de sus esposas, el primero comportándose como un canalla y creándose enemigos en Yanhuitlan y Acatlan, y el segundo perdiendo sus derechos en Yanhuitlan por sus tácticas agresivas. Al entrar en el siglo XVIII, la política de los cacicazgos había cambiado en la Mixteca Alta, pero ninguno de los dos aceptó el reducido papel político de los caciques y ambos sufrieron las consecuencias. El casamiento de don Martín Carlos de Villagómez y doña Juana Faustina Pimentel en 1739 también fue ambicioso, uniendo el número máximo de títulos en la historia colonial de la Mixteca. Pero los factores que motivaron esta alianza eran el prestigio y el acceso al capital. La pareja tenía poco interés en la política y dedicó sus esfuerzos a cobrar sus rentas. El segundo matrimonio de don Martín Carlos muestra el mismo patrón. Las demás uniones en los años posteriores fueron con no-indígenas, un síntoma de la asimilación en marcha de los Villagómez a la sociedad criolla. Por entonces, los asuntos políticos de los pueblos habían perdido su encanto y los caciques se preocupaban más por mantener y mejorar su posición de clase. 
En todo, las alianzas de los Villagómez a largo plazo hubo poca integración política o social entre la Mixteca Alta y la Baja. ${ }^{49}$ Yanhuitlan, un turrón grande para don Diego en los 1660, se perdió por las acciones de sus sucesores. Extraordinariamente, los cacicazgos en la Baja de Acatlan, Petlalcingo, Silacayoapan, y posiblemente Tonala, quedaron en la familia Villagómez hasta el final.

Recibido el 6 de noviembre de 2007

Aceptado el 21 de febrero de 2008

49 Menegus Bornemann, escribiendo sobre la Mixteca en el siglo XVI, en cambio pone el énfasis sobre la integración entre las tres regiones de la Alta, Baja y Costa efectuado por las alianzas matrimoniales de los nobles, y el hecho de que varios señoríos de la Alta tenían posesiones en la Baja. Es muy posible que hubiera más integración entre las regiones antes de la época colonial tardía, la época que trato en el presente trabajo. Pero también he procurado demostrar que hay que tomar en cuenta, en cuanto que sea posible, las relaciones — políticas, económicas, sociales y culturales — involucradas en las alianzas. Desde este punto de vista, podemos esperar cierto grado de variación en la forma y en el éxito de las alianzas en el espacio y en el tiempo. Menegus Bornemann, Margarita: "Gobierno y territorialidad...", págs. 2-7. 